\title{
Comunicación
}

\section{Población de Perros Callejeros del Municipio Camagüey, Cuba}

\author{
Stray Dog Population of the Municipality of Camagüey, Cuba \\ Iván Peña G. ${ }^{1,2}$, Florangel Vidal F. ${ }^{1}$, Aliesky Hernández R. ${ }^{1}$
}

\section{Resumen}

Con el objetivo de estimar la población de perros callejeros en Camagüey, Cuba, se realizó un censo de la población canina callejera en cuatro barrios de la ciudad de Camagüey durante los meses de septiembre a diciembre de 2015. Se recopilaron datos sobre sexo del perro, presencia de ectoparásitos (garrapatas y pulgas) y enfermedades dermatológicas. Asimismo, se recolectó material fecal encontrado en calles y centros públicos. El número de perros por barrio varió entre 45 y 75 , donde el $62 \%$ de las observaciones correspondieron a perros con lesiones en piel o con presencia de ectoparásitos. El 61.7\% de las muestras fecales fue positiva a huevos de parásitos gastrointestinales, mayormente de los géneros Ancylostoma y Toxocara.

Palabras clave: perros callejeros, contaminación ambiental, contaminación biológica, riesgo biológico, parasitismos en zonas urbanas

\section{Abstract}

In order to estimate the population of dogs in the streets of Camaguey, Cuba a field survey was carried out on stray dogs in four neighbourhoods of the Camagüey city during September to December 2015. Data related to sex of the dog, presence of ectoparasites (ticks and fleas) and skin diseases was collected. Besides, faecal material was collected from roads and public places. The number of stray dogs per neighborhood ranged from 45 to 75 . Furthermore, $62 \%$ of the observations corresponded to dogs with skin lesions or presence of ectoparasites and $61.7 \%$ of the fecal samples were positive for eggs of gastrointestinal parasites, mostly of the genera Ancylostoma and Toxocara.

Keywords: stray dogs, environmental pollution, biological pollution, biohazard, parasitism in urban areas

\footnotetext{
${ }^{1}$ Universidad de Camagüey Ignacio Agramonte Loynaz, Camagüey, Cuba

${ }^{2}$ E-mail: ivan.pena@reduc.edu.cu
}

Recibido: 3 de abril de 2016

Aceptado para publicación: 6 de julio de 2016 


\section{INTRODUCCIÓN}

Se define como perro callejero aquel que ha sido abandonado o, que aun teniendo dueño, deambula libremente por las áreas públicas sin control directo (Brusoni et al., 2007; Guerra et al., 2007; WSPA, 2007; Yaliní et al., 2014). En muchos países, la mayoría de perros que se definen como callejeros tienen dueño, pero se les permite vagar por sitios públicos durante parte o todo el día (Yaliní et al., 2014).

En América Latina existe un alto número de perros deambulando por las calles, llevando consigo el peligro potencial de transmisión de enfermedades zoonóticas (Guerra, et al., 2007). La contaminación ambiental se evidencia en la acumulación y posterior dispersión de las excreciones de los perros callejeros, incluyendo las de aquellos con dueños irresponsables (Guerra et al., 2007). El objetivo del presente trabajo fue estimar la población de perros callejeros en Camagüey, Cuba.

\section{Materiales y Métodos}

Se realizó un censo de la población canina que deambula en el casco histórico y en los barrios de Garrido, Saratoga, La Belén y Florat, de la ciudad de Camagüey, durante los meses de septiembre a diciembre de 2015 .

Las pesquisas se realizaron en los lugares públicos, tales como calles principales, cafeterías, centros comerciales y centros de elaboración de alimentos, entre otros. Se realizaron tres mediciones mensuales, haciendo dos recorridos al día, en los horarios de 06:00 a 09:00 y de 18:00 a 21:00, promediándose los resultados de las observaciones.

Se consideró el sexo de los canes, la presencia de ectoparásitos (garrapatas y pulgas) y enfermedades dermatológicas de diversa naturaleza. Asimismo, se recolectó material fecal en forma aleatoria de centros públicos y calles de mayor aglomeración peatonal. Las muestras fueron procesadas mediante la técnica de flotación para determinar la presencia de huevos de parásitos. Cada muestra fue procesada dos veces antes de determinar su negatividad.

No fue posible atrapar a todos los perros para determinar el sexo y la presencia de ectoparásitos, de allí que en algunos casos se les atrajo con algo de alimento para observarlos y en otros casos se utilizó una cámara fotográfica. Para la observación de los ectoparásitos, se tuvo en cuenta las zonas que suelen afectarse más, como la región lumbosacra, la zona del cuello, las axilas y las orejas. Las lesiones en piel que se reportaron fueron las más evidentes, en la mayoría de casos coincidiendo con los animales que presentaban abundantes lesiones epidérmicas. En la recolección de heces del piso, se tomó en consideración su consistencia, seleccionando las que se apreciaban más frescas. Se colectó entre 5 y $10 \mathrm{~g}$ de material fecal por muestra.

El recorrido se realizó en el siguiente orden: Garrido, Saratoga, Florat, la Belén y Centro Histórico, cubriendo un área de 15 $\mathrm{km}$ aproximadamente. El recorrido fue realizado en bicicleta, contemplando las rutas donde existen cafeterías, centros comerciales, centros de elaboración de alimentos, terminal de ferrocarriles, etc. En el caso del casco histórico de la ciudad, el recorrido se realizó a pie.

Los datos se procesaron mediante la prueba del Chi cuadrado utilizando el programa SPSS Statistics v. 21.0. Los resultados de frecuencia se expresaron en forma porcentual.

\section{Resultados y Discusión}

El promedio de perros varió entre $45 \mathrm{y}$ 75 por barrio (Cuadro 1), cantidad bastante inferior a la reportada en viviendas de Camagüey (Guerra et al., 2007). La mayor 
Cuadro 1. Promedio de perros callejeros en las calles y lugares públicos de la ciudad de Camagüey, Cuba (septiembre-diciembre de 2015)

\begin{tabular}{lccccc}
\hline & $\begin{array}{c}\text { Casco } \\
\text { histórico }\end{array}$ & Garrido & Saratoga & La Belén & Florat \\
\hline Septiembre & 75 & 58 & 56 & 65 & 52 \\
Octubre & 65 & 52 & 64 & 50 & 62 \\
Noviembre & 54 & 51 & 52 & 51 & 52 \\
Diciembre & 68 & 55 & 62 & 51 & 45 \\
\hline Promedio & 65.5 & 54.0 & 58.5 & 54.3 & 52.8 \\
\hline
\end{tabular}

Cuadro 2. Frecuencia de parásitos hallados en 547 muestras de materia fecal canina recolectada en calles y lugares públicos de Camagüey, Cuba (2015)

\begin{tabular}{lc}
\hline Especies de parásitos & $\%$ \\
\hline Ancylostoma $\mathrm{sp}$ & 44.6 \\
Toxocara $\mathrm{sp}$ & 27.6 \\
Trichuris $\mathrm{sp}$ & 3.0 \\
Coccidias & 2.0 \\
Ancylostoma + Toxocara & 14.0 \\
Ancylostoma + Trichuris & 2.0 \\
Ancylostoma + coccidia & 1.0 \\
Toxocara más coccidios & 2.0 \\
Ancylostoma + Dipilidium & 1.1 \\
Ancylostoma + Toxocara + & 2.7 \\
\multicolumn{1}{c}{ Trichuris } & \\
\hline Total & 100 \\
\hline
\end{tabular}

cantidad de perros fue encontrada en la zona del casco histórico de la ciudad, lugar donde se encuentra la mayor cantidad de personas; aspecto que puede ser perjudicial a la salud humana debido a la existencia de parásitos en heces fecales en el suelo de lugares públicos (Marder et al., 2004).
Guerra et al. (2007) plantean que independientemente de la repercusión zoonótica, la presencia de perros callejeros afectados por enfermedades dermatológicas muestran un aspecto insalubre de la imagen urbana, lo que se agrava con la diseminación de sus excreciones y de los residuales sólidos humanos.

El incremento de perros callejeros es una manifestación de una serie de factores socioeconómicos y culturales que tiene su origen en la insuficiente educación ciudadana y en una deficiente legislación sobre el impacto de la población canina en el medio ambiente y la salud pública (Álvarez y Domínguez, 2001; Ibarra et al., 2006; Yaliní et al., 2014).

En total, se llegaron a realizar 1,140 observaciones de perros callejeros durante los cuatro meses, siendo posible que muchas de estas observaciones correspondan a los mismos perros. De estas observaciones, el 61\% correspondió a perros machos, sin diferencia significativa con la frecuencia de hembras (39\%). Asimismo, 707 observaciones (62\%) correspondieron a perros con lesiones en piel o con presencia de ectoparásitos.

Los perros callejeros que presentaron lesión en piel o presencia de ectoparásitos fue probablemente a consecuencia de una 
inadecuada alimentación y el estrés que favorecía un estado de inmunosupresión (Scott et al., 2001; Mencho et al., 2003). Los perros callejeros estarían más propensos a sufrir afecciones de piel como sarna sarcóptica y demodéctica, o por agentes bacterianos y micóticos. Estos perros representan un foco de infección para otros animales que son paseados en parques o calles por sus propietarios (Güttler, 2005; Guerra et al., 2007; Yaliní, et al., 2014).

Se recolectaron 887 muestras de heces, donde el $61.7 \%$ fue positiva a huevos de parásitos gastrointestinales. En el Cuadro $2 \mathrm{se}$ muestran los parásitos más frecuentes hallados en las muestras fecales. Los huevos más frecuentes correspondieron a los géneros Ancylostoma (44.6\%) y Toxocara (27.6\%), lo cual, desde el punto de vista de la salud pública y veterinaria, adquiere gran importancia por ser parásitos de importancia zoonótica.

La toxocariosis es una enfermedad parasitaria accidental en el hombre, que se produce por la ingestión de huevos larvados del nematodo del perro, Toxocara canis (Noemi et al., 1992; Minvielle et al., 1999). Esta infección es considerada como problema de salud mundial y es relativamente frecuente en zonas de climas templados y tropicales, principalmente en el ámbito urbano (Espinoza et al., 2003).

La contaminación ambiental por huevos y larvas de parásitos caninos constituye un riesgo de salud pública (Acha y Szyfres, 2003; Botero y Restrepo, 2003; Radman et al., 2006). El perro doméstico es el principal agente involucrado en la contaminación de parques y plazas públicas (Armstrong et al., 2011), siendo la población infantil uno de los grupos más expuestos a los focos de transmisión (Milano y Oscherov, 2005; Olivares et al., 2014).
Los parásitos y las frecuencias encontrados en el presente estudio difieren de resultados presentados por otros investigadores (Marder et al., 2004; Olivares et al., 2014; Serrano-Martínez et al., 2014; Yaliní et al., 2014).

\section{Literatura Citada}

1. Acha N y Szyfres B. 2003. Zoonosis y enfermedades transmisibles comunes al hombre y a los animales. $3^{\mathrm{a}}$ ed. Washington DC: Organización Panamericana de la Salud. 398 p.

2. Alvarez E, Domínguez, J. 2001. Programa para el control integral de la población canina. AMMVEPE 12(3): 83-91.

3. Armstrong $W$, Oberg C, Orellana $J$. 2011. Presencia de huevos de parásitos con potencial zoonótico en parques y plazas públicas de la ciudad de Temuco, Región de La Araucanía, Chile. Arch Med Vet 43: 127-134. doi: 10.4067/S0301732X2011000200005

4. Botero DD, Restrepo M. 2003. Parasitosis humanas. $4^{\mathrm{a}}$ ed. Medellín, Colombia: Corporación para Investigaciones Biológicas. $542 \mathrm{p}$.

5. Brusoni C, Fernández Canigia J, Lara J, Dezzotti A. 2007. Tamaño y estructura de la población canina en San Martín de los Andes (Neuquén). Analecta Vet 27: 11-23.

6. Espinoza Y, Huapaya P, Sevilla $C$, Náquira C. 2003. Toxocariosis humana: seroprevalencia en población de Lima mediante la técnica de ELISA. An Fac Med 64: 228-232.

7. Guerra Y, Echagarrúa Y, Marín C, Mencho J, Marín A, Pascual T, Artze $S$, Abad G 2007. Factores que conllevan al abandono de perros en una región de Cuba. REDVET 8(12). [Internet]. Disponible en: http://www.veterinaria. org/revistas/redvet/n121207/120704.pdf 
8. Güttler V. 2005. Análisis de algunas características de la población canina relacionadas con mordeduras e hidatidosis humana en la provincia de Valdivia. Tesis de Médico Veterinario. Chile: Univ. Austral de Chile. 60 p.

9. Ibarra L, Espínola F, Echeverría M. 2006. Factores relacionados con la presencia de perros en las calles de la ciudad de Santiago, Chile. Avances Cienc Vet 21: 21-26. doi: 10.5354/07195273.2006.1384

10. Marder G. Bottinelli S, Meza Fleitas O, Lotero Z, Ruiz D, Peiretti R, Arzú R. 2004. Infestación parasitaria en suelos y materia fecal de perros y gatos de la ciudad de Corrientes. Rev Vet 15(2): 70-72.

11. Mencho J, Guerra Y, Vale M, García S. 2003. Demodicosis canina en el municipio de Camagüey. REDVET 7(4). [Internet]. Disponible en: http:// www.veterinaria.org/revistas/redvet/ n070703.html

12. Milano A, Oscherov E. 2005. Contaminación de aceras con enteroparásitos caninos en Corrientes, Argentina. Parasitol Latinoam 60: 82-85.

13. Minvielle M, Niedfeld M, Ciarmela M, Basualdo J. 1999. Toxocariosis causada por Toxocara canis aspectos epidemiológicos. Enf Infec Microbiol Clin 17:300-306.

14. Noemi I, Viovy A, Cerva J, Gottlieb B, Roncone E, Quera R, et al. 1992. Per- fil clínico de la toxocariasis en pediatría. Parasitol Día 16: 91-97.

15. Olivares P, Valenzuela G, Tuemmers C, Parodi J. 2014. Descripción de parásitos presentes en muestras fecales recolectadas en plazas del sector céntrico de la ciudad de Temuco, Chile. Rev Inv Vet Perú 25: 406-413. doi: 10.15381/ rivep.v25i3.10119

16. Radman N, Archelli S, Burgos L, Del Valle M. 2006. Toxocara canis en caninos: prevalencia en la ciudad de La Plata. Acta Bioquim Clin Latinoam 40: 41-44.

17. Scott D, Miller W, Griffin C. 2001. Parasitic skin diseases. In: Muller \& Kirk's small animal dermatology. $6^{\text {th }}$ ed. Philadelphia, USA: WB Saunders. p 423516.

18. Serrano-Martínez, Tantaleán M, Castro V, Quispe M, Casas G 2014. Estudio retrospectivo de frecuencia de parásitos en muestras fecales en análisis rutinarios de laboratorio. Rev Inv Vet Perú 25: 113-116. doi: 10.15381/rivep. v25i1.8476

19. [WSPA] World Society for the Protection of Animals. 2007. Censando poblaciones de perrosdeambulantes: guía metodológica. Londres: WSPA. 21 p.

20. Yaliní O, Falcón N, Zuazo J, Guevara B. 2014. Estimación de la población de perros callejeros en el distrito de Los Olivos, Lima, Perú. Rev Inv Vet Perú 25: 366-373. doi: 10.15381/rivep.v25i3.10114 